\title{
Effect of 2\% Lignocaine Solution in Pain During Removal of Nasal Pack
}

\author{
Ashish Dhakal, ${ }^{1}$ Bikash Lal Shrestha, ${ }^{1}$ Monika Pokharel ${ }^{1}$ \\ ${ }^{1}$ Department of ENT-HNS, Dhulikhel Hospital, Kathmandu University Hospital, Kavre, Nepal.
}

\begin{abstract}
Background: Nasal packing is commonly done after septal surgeries. Nonabsorbable nasal pack is used to minimize bleeding from surgery site, support the mucoperichondrial flaps, and minimize the risk of formation of septal hematomas and adhesions. However, these materials cause pain and discomfort in-situ as well as during removal. This study was done to evaluate the effect of $2 \%$ lignocaine rehydration of nasal pack on pain during pack removal. Methods: This prospective study was conducted on 60 patients who had undergone septoplasty. The patients were divided into 2 groups: Lignocaine and Normal saline group, with 30 patients each. In the Lignocaine group, $2.5 \mathrm{ml}$ of $2 \%$ of lignocaine was diluted with $2.5 \mathrm{ml}$ of distilled water and was injected into the nasal pack; and in Normal saline group, $5 \mathrm{ml}$ of normal saline was injected into the nasal pack. Nothing was injected to the left nostril, which acted as a control, in both groups. All patients were asked severity of pain during removal of nasal packing by VAS. Results: In lignocaine group, mean pain score was $3.73 \pm 1.63$ on lignocaine side and $6.23 \pm 1.69$ on control side $(U=109.5, p<0.001)$. In Normal saline group, it was $6.5 \pm 1.7$ on normal saline side and $6.23 \pm 1.96$ on control side ( $U=425.5$, $\mathrm{p}=0.711$ ). On comparing VAS between lignocaine and normal saline group, pain was significantly lower in the lignocaine group ( $U=112.5, p<0.001)$ Conclusion: Rehydrating nasal pack with $2 \%$ topical lignocaine is a useful method to reduce pain during nasal pack removal.
\end{abstract}

Keywords: lignocaine; local anesthetic; nasal pack; pain management; postoperative pain; septoplasty.

\section{INTRODUCTION}

Septoplasty, for symptomatic deviated nasal septum, is a commonly practiced surgery in ENT. After this surgery, nonabsorbable nasal packs have been commonly used to minimize bleeding from the surgery site. Additionally, they also support the septal mucoperichondrial flaps and minimize the risk of formation of septal hematomas and adhesions. ${ }^{1,2}$ One of the main concerns about using packing is that the removal is usually very painful and can be very bothersome. This procedure may even result in syncope by the activation of the vasovagal reflex system. There have been a few studies suggesting that nasal packs should not be used because removal from the nose causes serious discomfort and is painful. ${ }^{3-6}$ Many patients who have undergone nasal surgery report that the removal of the pack was the most painful part of the experience. ${ }^{5,7,8}$ Lignocaine is an amide group local anaesthetic effective in infiltration anesthesia and nerve block. It is not affected by heat, acids or alkalines. Commercial preparation of lignocaine $2 \%$ with adrenaline has a longer duration of action and decreases bleeding. It has a rapid onset of action, duration of action is medium. It has the ability to

penetrate the tissues rapidly. Mean plasma half-life is 2 hour. ${ }^{9}$ The aim of this study was to evaluate the effect of lignocaine and normal saline soaked nasal packing during removal of the packs.

\section{METHODS}

A hospital based, prospective, single blinded, comparative study was conducted in the department of Otorhinolaryngology and Head and Neck surgery in Dhulikhel Hospital, Kathmandu University Hospital, Kavre from October 2017 to September 2018. Approval from Institutional Review Committee of Kathmandu University School of Medical Sciences Dhulikhel Hospital was taken, and informed consent obtained from the patient before conducting the study. This study was carried out in patients who underwent septoplasty for deviated nasal septum under general anesthesia, and who were categorized as American Society of Anesthesiologists (ASA) grade I to II. All the patients were made familiar with a standard $10 \mathrm{~cm}$ visual analogue scale (VAS) on pre-operative visit, in which 0 represents no pain at all and 10 represents the

Correspondence: Dr. Ashish Dhakal, Department of ENT-HNS, Dhulikhel Hospital, Kathmandu University Hospital,

Kavre, Nepal. Email: ashishdhakal@gmail.com. Phone: +977-9841482469. DOI: 10.3126/jcmsn.v15i2.22629. Article Received: 2019-02-06. Article accepted: 2019-5-20. 
worst pain imaginable. Conventional septoplasty was carried out under general anesthesia and in all patients and expandable polyvinyl acetate nasal packing that expand upon contact with fluid was used. The postoperative analgesia included Ibuprofen $400 \mathrm{mg}+$ Paracetamol $500 \mathrm{mg}$ combination thrice daily and Ketorolac $30 \mathrm{mg}$ intravenous when needed. The packs were removed on the second postoperative day. During nasal pack removal, the subjects were randomly divided into 2 groups: the Lignocaine group $(2 \%$ lignocaine $\mathrm{HCl})$ and the Normal saline group $(0.9 \% \mathrm{NaCl})$ using lottery method. Subjects were blinded to which group they belong to and what medication they received. A 23-gauge needle was used for direct application of the treatment to the pack, with care taken not to touch the patient. In the Lignocaine group, $2.5 \mathrm{ml}$ of $2 \%$ of lignocaine was diluted with $2.5 \mathrm{ml}$ of distilled water, and the $5 \mathrm{ml}$ solution was injected into the nasal pack on right side 15 minutes before removal of the pack. Nothing was injected to the left nostril, which acted as a control, and pack removed 15 minutes later. In the Normal saline group, $5 \mathrm{ml}$ of normal saline was injected into the nasal pack on right side 15 minutes before removal. Similarly, nothing was injected to the opposite nostril, and pack removed 15 minutes later. All patients were asked to evaluate the severity of pain during removal of nasal packing by VAS (range, 0 $10 ; 0=$ no pain and $10=$ intolerable pain). Adverse events such as vomiting and nausea, if present, were recorded. These procedures were done by the same team to minimize observer variations. Inclusion criteria was: Symptomatic deviated nasal septum undergone Septoplasty surgery with bilateral anterior nasal packing, Age $\geq 18$ years of either sex. Exclusion criteria were: History of previous nasal surgeries, Nasal polyposis, Allergic rhinitis, Chronic sinusitis, Patient with neurological and psychiatric disease, Patient with sensitivity to anesthetic agent in study, Patients unwilling to enroll in the study, Patient using medication for chronic pain. The Shapiro-Wilk test was used to check the normality of the quantitative data distribution. Non-normally distributed variables with the Mann-Whitney test. Statistical values of $p<0.05$ were considered significant. SPSS v. 21.0 for Windows (SPSS inc., Chicago, USA) was used for the statistical data analysis.

\section{RESULTS}

Total of 60 patients were enrolled in the study with 30 each in Lignocaine and Normal saline group with age ranging from $18-53$ years (mean age of $29.25 \pm$ 9.58 years). There were total 35 male $(58.3 \%)$ and
25 females $(41.7 \%)$ in the study. In Lignocaine group 14 male and 16 female, and in Normal saline

\begin{tabular}{|lcl|}
\hline \multicolumn{2}{|l|}{ Table 1. Patient demographics. } \\
\hline Variable & $\begin{array}{l}\text { Lignocaine } \\
\text { group }(\mathbf{n}=\mathbf{3 0})\end{array}$ & $\begin{array}{l}\text { Normal saline group } \\
(\mathbf{n}=\mathbf{3 0})\end{array}$ \\
Sex & & \\
Male & $14(46.67 \%)$ & $21(70 \%)$ \\
Female & $16(53.33 \%)$ & $9(30 \%)$ \\
Age (year) & $27.57 \pm 8.77$ & $29.47 \pm 11.14$ \\
\hline Values are presented as mean $\pm S D$ \\
\hline
\end{tabular}

group 21 male and 9 female (Table 1).

Pain score was recorded with VAS during nasal pack removal. In lignocaine group, mean pain score was $3.73 \pm 1.63$ on lignocaine side and $6.23 \pm$ 1.69 on control side $(U=109.5, p<0.001)$. In Normal saline group, mean pain score was $6.5+$ -

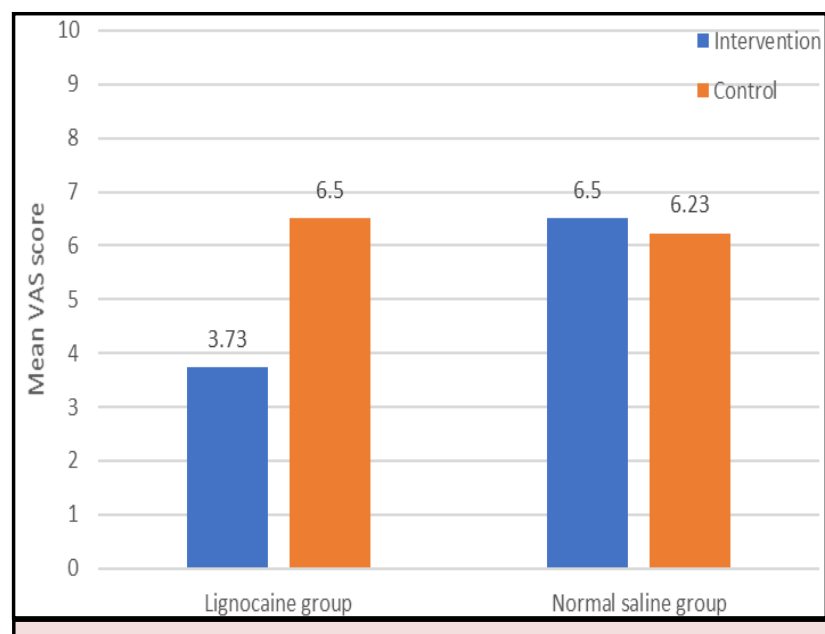

Figure 1. Pain scores during nasal pack removal.

1.7 on normal saline side and $6.23 \pm 1.96$ on control side ( $U=425.5, p=0.711)$ (Figure 1).

On comparing VAS between lignocaine and normal saline group, pain was significantly lower in the lignocaine group $(\mathrm{U}=112.5, \mathrm{p}<0.001)$.

\section{DISCUSSION}

Nasal packing is commonly done after septal surgeries. Nonabsorbable nasal pack is used to minimize bleeding from surgery site, for support to the mucoperichondrial flaps, and minimize the risk of formation of septal hematomas and adhesions. However, these materials cause pain and discomfort in-situ as well as during removal. It's been reported that even absorbable materials for nasal packing cause nasal discomfort and pain in the duration of nasal packing. Patients have described the pack removal event as the most unpleasant aspect of the perioperative experience. 
Various methods have been tried to decrease pain and make patient comfortable during pack removal. ${ }^{1,6,10-16}$ In our study, we used $2 \%$ topical lignocaine to rehydrate the nasal pack to investigate its analgesic effect during pack removal. Lachanas et al suggested that rehydration of Merocel packing with tetracaine solution $0.25 \%$ is effective in decreasing pain during nasal pack removal following septoplasty. ${ }^{1}$ Karaaslan et al concluded that adding meperidine to prilocaine 15 minutes before nasal pack removal helps by decreasing pain and provides mild sedative effect which lowers anxiety associated with the event. ${ }^{17}$ Buchanan et al used bupivacaine and Kuo et al used 5\% lidocaine ointment in their nasal packs during surgery and found they reduced early post-operative pain. But this method didn't help in reducing pain during pack removal. ${ }^{18,19}$ Lavy et al used $4 \%$ lignocaine solution to rehydrate Merocel pack and compared it with normal saline. They reported a reduction in the pain score on study side but the reduction wasn't statistically significant. ${ }^{10}$ Durvasula et al used 2\% lignocaine solution or normal saline for rehydrating nasal pack before removal. They didn't find any reduction of pain with both these methods. ${ }^{20}$ Our study had a different design than previous studies with intervention in one nostril and the other nostril being kept as a control in the same patient. This would help to reduce confounding variables. We found there was significant reduction in pain score between the lignocaine and control side, and also between lignocaine and normal saline group. This study has some limitations. Firstly, rate of systemic absorption in cases of topical lignocaine application from nasal mucosa is not known. This is required to use the maximal dose of drug for pain relief without causing unwanted side effects. Second, the sample size of our study was relatively small.

\section{CONCLUSION}

In our study, we rehydrated nonabsorbable nasal pack in patients, who underwent septoplasty, with Lignocaine and normal saline before removal. We conclude that topical lignocaine application to nasal packs provide better analgesia and less discomfort during pack removal. Therefore, 2\% topical lignocaine application to nasal packs would be a safe, inexpensive, and effective method to reduce pain during nasal pack removal in patient who have undergone septoplasty.

\section{ACKNOWLEDGEMENTS}

We would like to thank Dr. Pratiksha Pathak for her help in statistical analysis.

\section{REFERENCES}

1. Lachanas VA, Karatzias GT, Pinakas VG, Hatziioannou JK, Sandris VG. The use of tetracaine $0.25 \%$ solution in nasal packing removal. Am J Rhinol. 2006 Oct;20(5):483-4. PMID: 17063742

2. Ardehali MM, Bastaninejad S. Use of nasal packs and intranasal septal splints following septoplasty. Int J Oral Maxillofac Surg. 2009 Oct;38(10):1022-4. PMID: 19577902 DOI: 10.1016/j.ijom.2009.05.012

3. Watson MG, Campbell JB, Shenoi PM. Nasal surgery: does the type of nasal pack influence the results? Rhinology. 1989 Jun;27(2):10511. PMID: 2781213

4. el-Silimy O. Inferior turbinate resection: the need for a nasal pack. J Laryngol Otol. 1993 Oct;107(10):906-7. PMID: 8263387

5. Orlandi RR, Lanza DC. Is nasal packing necessary following endoscopic sinus surgery? The Laryngoscope. 2004 Sep;114(9):1541-4. PMID: 15475778 DOI: $10.1097 / 00005537-$ 200409000-00007

6. Apuhan T, Yildirim YS, Gulcu N, Koçoglu H, Karagöz Y. The effect of prilocaine or levobupivacaine infiltration on pain during nasal packing removal. Otolaryngol--Head

Neck Surg Off J Am Acad Otolaryngol-Head Neck Surg. 2011 Sep;145(3):418-21. PMID: 21613628 DOI: $10.1177 / 0194599811410660$

7. Özkırış M, Kapusuz Z, Saydam L. Comparison of nasal packs with transseptal suturing after nasal septal surgery. Am J Otolaryngol. 2013 Aug;34(4):308-11. PMID: 23394817 DOI: 10.1016/j.amjoto.2012.12.012

8. Laing MR, Clark LJ. Analgesia and removal of nasal packing. Clin Otolaryngol Allied Sci. 1990 Aug 1;15(4):339-42.

9. Benowitz NL, Meister W. Clinical pharmacokinetics of lignocaine. Clin Pharmacokinet. 1978 Jun;3(3):177-201.

10. Lavy JA, Small GV, Jay N, Radcliffe GJ. A prospective randomized controlled study of $4 \%$ lignocaine solution in Merocel nasal pack removal. Rhinology. 1996 Dec;34(4):219-21. PMID: 9050100.

11. Laing MR, Clark LJ. Analgesia and removal of nasal packing. Clin Otolaryngol Allied Sci. 1990 Aug;15(4):339-42. PMID: 2225503 DOI: 10.1111/j.1365-2273.1990.tb00479.x

12. Gencer ZK, Ozkiriş M, Gencer M, Saydam L. Comparison of ropivacaine, bupivacaine, prilocaine, and lidocaine in the management of pain and hemorrhage during nasal pack 
removal. Am J Rhinol Allergy. 2013 Oct;27 (5):423-5. PMID: 24119607 DOI: 10.2500/ ajra.2013.27.3945

13. Mutlu V, Kaya Z. Comparison of the effect of the lidocaine, tetracaine, and articaine application into nasal packs on pain and hemorrhage after septoplasty. Eur Arch Oto-Rhino-Laryngol Off J Eur Fed Oto-RhinoLaryngol Soc EUFOS Affil Ger Soc Oto-Rhino -Laryngol - Head Neck Surg. 2018 Oct;275 (10):2481-5. PMID: 30088077 DOI: 10.1007/ s00405-018-5084-3

14. Yilmazer C, Sener M, Yilmaz I, Erkan AN, Cagici CA, Donmez A, et al. Pre-emptive analgesia for removal of nasal packing: A double-blind placebo controlled study. Auris Nasus Larynx. 2007 Dec;34(4):471-5. PMID: 17337141 DOI: 10.1016/j.anl.2006.11.013

15. Abu-Samra MM, Ismaeil WA. Pre-emptive oral dextromethorphan reduces both postoperative and packing removal pain in patients undergoing nasal surgery. Saudi Med J. 2009 Feb;30(2):214-8. PMID: 19198708

16. Tulunay EO, Tulunay FC, Gulmez SE, Ergun $\mathrm{H}$, Demireller A. The analgesic efficacy of dipyrone during removal of nasal packings after septal surgery. J Headache Pain. 2004 Dec;5(4):243-6. PMCID: PMC4749057 DOI: 10.1007/s10194-004-0133-2

17. Karaaslan K, Yilmaz F, Gulcu N, Yigit B, Kocoglu $H$. The effect of prilocaine and prilocaine plus meperidine infiltration on the pain during nasal packing removal. Rhinology. 2007 Dec;45(4):321-4. PMID: 18085028

18. Buchanan MA, Dunn GR, Macdougall GM. A prospective double-blind randomized controlled trial of the effect of topical bupivacaine on post-operative pain in bilateral nasal surgery with bilateral nasal packs inserted. J Laryngol Otol. 2005 Apr;119 (4):284-8. PMID: 15949082 DOI: $10.1258 / 002221505402032$

19. Kuo MJ, Zeitoun H, Macnamara M, Wagstaff K, Carlin WV, Turner N. The use of topical $5 \%$ lignocaine ointment for the relief of pain associated with post-operative nasal packing. Clin Otolaryngol Allied Sci. 1995 Aug;20 (4):357-9. PMID: 8548972

20. Durvasula VSP, Brewis C, Syeda F, Leong P. Lignocaine as a topical analgesia for postoperative nasal pack removal: a prospective, randomized, double-blind, controlled trial. J Laryngol Otol. 2005 May;119(5):348-51. P M I D : $\quad 15949096$ D O I : $10.1258 / 0022215053945859$

Citation: Dhakal A, Shrestha LB, Pokharel M. Effect of 2\% Lignocaine Solution in Pain During Removal of Nasal Pack. JCMS Nepal. 2019; 15(2):80-3. 